\title{
Incidência de Escabiose entre Índios da Etnia Terena
}

Scabies Incidence among Indians of the Terena Population

\author{
Professor Doutor Antonio Neres Norberg (Medicina - UniFOA, UNIG, UAA) \\ antonio.norberg@foa.org.br \\ Professor Doutor Edwin Alberto Pile Maure (Pesquisador - INIDA - Cabo Verde) \\ Epile@inida.cv
}
Professora Doutora Margareth Maria de Carvalho Queiroz (Pesquisadora - FIOCRUZ, UNIG) mmcqueiroz@uol.com.br
Professor Especialista Aluízio Antonio de Santa Helena (Farmácia - UNIG) Mestrando da Universidad Autónoma de Asunción, Paraguay aluizioantonio@unig.br

Professor Especialista Paulo Roberto Blanco Moreira Norberg (UniABEU) Mestrando da Universidad Autónoma de Asunción, Paraguay internacional@swissinfo.org
Professor Especialista Fabiano Guerra Sanches (Farmácia - UNIG, FTESM) Mestrando da Universidad Autónoma de Asunción, Paraguay fab.gs@bol.com.br
Professora Especialista Ana Carolina Torres (Biologia - UniABEU, FTESM) Mestranda da Universidad Autónoma de Asunción, Paraguay ana.biovet@bol.com.br

\section{Resumo}

Os autores apresentam os resultados preliminares da incidência de escabiose entre índios da etnia Terena, pertencentes à aldeia Moreira, município de Miranda, Mato Grosso do Sul. A pesquisa foi realizada no mês de janeiro de 2005 entre 259 índios que compareceram ao posto de saúde da aldeia para atendimento médico e paramédico, realizado pela equipe de saúde da Universidade lguaçu. O diagnóstico foi realizado pelas características clínicas da doença e em alguns casos pela confirmação laboratorial pelo encontro do Sarcoptes scabiei através do processo da fita gomada. Os resultados demonstraram 23 casos positivos, o que corresponde a 8,8\% do total examinado.

Palavras chave: escabiose, sarna, índios Terena 
The authors presents the preliminary results of incidence of the destruction among Indians from the Terena population, belongings to the settlement Moreira, district of Miranda, Mato Grosso do Sul. The research was realized in January 2005 among 259 Indians that came out of the settlement health station to the medical attendance, took in by the healthiness staff from the Iguaçu University. The diagnosis was made by clinical features of the disease and in some cases by the laboratory evidence for the meeting of the Sarcoptes scabiei through the process of the segmented tape. The results displayed 23 positive cases, that replies to $8,8 \%$ from total of which were examined.

Key-words: Destruction, Scabies, Indians from Terena.

\section{Introdução}

A escabiose é uma dermatose popularmente conhecida como sarna, causada pelo ácaro Sarcoptes scabiei, sendo considerada de distribuição mundial. Ocorre em seres humanos de todas as raças e classes sociais em todos os climas e regiões do mundo.

O parasita é transmitido pelo contato entre indivíduos sadios e portadores da infecção, principalmente pela coabitação e intimidade, comum entre indivíduos que compartilham o mesmo leito. Esses ácaros podem sobreviver durante alguns dias no ambiente, sendo que a escabiose pode ser facilmente contraída por pessoas que entram em contato com locais que tenham sido ocupados pelos doentes, como em hotéis, hospitais, quando se sentam em sofás ou bancos ou deitam-se em camas anteriormente usadas por eles. A doença tem sido relatada durante guerras sob a forma de epidemia, nos acampamentos entre militares, em conseqüência da falta de higiene e promiscuidade em que vivem grandes aglomerados humanos (REY, 1991; MANDELL E COL., 2000; BATISTA E COL., 2001; VERONESI \& FOCACCIA, 2002).

Segundo Orkin \& Mainbach (1985), outro mecanismo de transmissão é o contato com animais domésticos, como o cão, porém nesse caso, trata-se de uma doença autolimitada e causada por subespécies que praticamente não tem especificidade para seres humanos.

Os sintomas da doença aparecem geralmente uma semana após o contágio. . Sua característica clínica marcante é o prurido, mais acentuado à noite, em conseqüência da temperatura mais elevada que se produz sob os cobertores (REY, 1991; NEVES E COL., 1998; VERONESI \& FOCACCIA, 2002). As lesões geralmente são constituídas por escoriações mais ou menos generalizadas, apresentando pequenas vesículas pruriginosas, pústulas e túneis ou galerias na face lateral dos dedos e das mãos, cotovelos, joelhos e ao redor das axilas. O túnel ou galeria aparece como uma pequena mancha irregular, com cerca de dois a três milímetros. Lesões características podem ocorrer com pápulas pruriginosas na vulva, nádegas, escroto e pênis. Além das citadas, existem outras formas especiais de apresentação clínica da escabiose. Segundo Rey (1991) a chamada sarna norueguesa é geralmente observada entre pacientes imunodeficientes, apresentando lesões crostosas exuberantes com abundância de parasitas. Essas lesões são acompanhadas de hiperqueratose e paraqueratose, que dão origem às crostas. Localizam-se de preferência na palma das mãos e planta dos pés, mas pode ser disseminada, invadindo outras regiões, inclusive o couro cabeludo, onde pode provocar alopécia (REY, 1991). Esse autor relatou 
ainda que além do quadro clínico citado por vários autores, ocorre também eritemas e formação de pápulas e vesículas que evoluem para a forma nodular, e podem permanecer por vários meses, mesmo após a cura da infecção.

Outro problema preocupante causado pelo S. scabiei foi relatado por Orkin (1993) e está relacionado com o parasitismo em indivíduos imunodeprimidos (HIV), onde as lesões são mais disseminadas e resistentes ao tratamento antiparasitário. Nos casos citados, as lesões são ricas em parasitas e concentram-se mais na região anogenital. São formas clínicas altamente contagiosas e o prurido é proporcional ao comprometimento da imunidade celular. Por outro lado, Obanjo (2001) relatou que indivíduos imunodeprimidos em conseqüência das infecções pelo Vírus da lmunodeficiência Humana (HIV), apresentam a forma clínica crostosa, que geralmente acomete esses pacientes, além de idosos debilitados ou com deficiência do sistema imune ou imunossuprimidos por outras causas. Nesses casos, as lesões crostosas oferecem maior chance para contaminação secundária por elementos bacterianos ou fúngicos, causando graves infecções. Este grave quadro clinico já foi descrito em vários países, inclusive no Brasil.

Este trabalho teve como objetivo o diagnóstico e tratamento da escabiose em índios da etnia Terena pertencentes à aldeia Moreira, localizada no município de Miranda, Mato Grosso do Sul.

\section{Casuística e Método}

A pesquisa foi realizada no mês de janeiro de 2005, e os pacientes citados compareceram ao posto de saúde da aldeia para atendimento médico e paramédico, e apresentavam queixas clínicas variadas. O diagnóstico da escabiose foi realizado considerando-se as características clínicas da doença e levando-se em conta outros casos de escabiose no grupo familiar. A confirmação laboratorial foi realizada em alguns pacientes pela demonstração dos parasitas mediante a aplicação de uma fita gomada transparente sobre a pele da região afetada. Em seguida, a fita foi colocada sobre uma lâmina de microscopia e examinada ao microscópio.

\section{Resultados e Discussão}

Os resultados mostraram 23 casos positivos entre os 259 índios examinados, o que corresponde a $8,8 \%$ do total avaliado. Estudos realizados por vários pesquisadores, em várias partes do mundo, mostraram a distribuição cosmopolita da parasitose em questão. Embora com ampla distribuição mundial, existem grupos populacionais que praticamente estão livres da doença. Levantamentos epidemiológicos realizados por Mendes (1990) e Lofredo e col. (2001) mostraram que a escabiose constitui um dos grandes problemas de saúde da população, sendo mais incidente nos grupos social, econômico e culturalmente desassistidos. Quando esses problemas são associados às doenças infecciosas e parasitárias, eles agravam o quadro de saúde desfavorável da população. Muitos casos de escabiose deixam de ser registrados pelos profissionais de saúde por considerá-los de pouca importância patogênica. Desta maneira, Silva e col. (1985) relataram que as doenças ditas parasitárias ocupam sempre posição de pouco destaque nas estatísticas européias e americanas. Isso acontece porque essas doenças, apesar de interferirem na qualidade de vida, não são letais. Sérias complicações podem ocorrer nos pacientes parasitados; as lesões 
pruriginosas produzidas pelos parasitas favorecem pela coçagem a penetração e a implantação de elementos bacterianos, sendo estafilococos e estreptococos patogênicos os mais freqüentes. Esses agentes microbianos causam com muita freqüência piodermites secundárias. Tais piodermites foram também observadas pela nossa equipe em aproximadamente $50 \%$ dos casos atendidos. A piodermite purulenta secundária conduz com freqüência a uma conduta clínica ineficaz. Constatamos que vários pacientes foram submetidos ao tratamento com penicilina (Benzetacil). Caso a bactéria fosse sensível ao antibiótico citado, poderia ocorrer o controle da infecção bacteriana secundária, porém a dermatose parasitária continuava, considerando a ineficácia da penicilina sobre o agente da escabiose. Vários desses pacientes voltavam à consulta médica queixando-se da continuidade do prurido, e nessas ocasiões julgamos que por falta de um antiparasitário ideal, os pacientes eram tratados apenas com anti-histamínicos. Tal procedimento melhorava temporariamente o prurido, mas não eliminava o S. scabiei.

Vários autores como Rey (1991). Neves e col. (1998), Veronesi \& Focaccia (2002) consideraram que o contato inter-humano, além do uso de roupas contaminadas entre outros mecanismos, constituem importantes fontes de contaminação pelo S. scabiei. Nossas observações sobre os hábitos dos índios estudados corroboram tais afirmações. Várias famílias usam redes que permanecem armadas em varandas ou na sombra de árvores, sendo utilizadas por vários indivíduos. Entre os usuários, verificamos a presença de várias pessoas com escabiose, facilitando a transmissão do agente. Outro mecanismo que consideramos importante são as indumentárias usadas durante as festividades, consideradas de uso coletivo.

Outros pesquisadores também se dedicaram ao estudo da escabiose entre povos indígenas. Lofredo e col. (2001) relataram a investigação e tratamento de uma epidemia de escabiose ocorrida em 1994 na aldeia onde habitam os índios da etnia Panará, na região centro-oeste do parque indígena do Xingú. A população era constituída por 168 índios e todos eram acometidos pela escabiose. O exemplo citado mostra a grande capacidade do agente em se transmitir para outros hospedeiros.

Alvares e col. (1991) realizaram uma pesquisa que envolveu uma comunidade de índios da etnia Xavante, no município de Pimenta Barbosa, em Mato Grosso, e observaram uma alta prevalência de escabiose, que correspondia a 66\% dos indivíduos daquela aldeia. Os autores consideraram o hábito de vestir-se associado à falta de higiene corporal e de limpeza correta das roupas como sendo os principais responsáveis pela alta prevalência da doença.

No dia 19 de abril comemora-se o dia do índio e nessas ocasiões as festividades e competições esportivas ocorrem com muito entusiasmo entre as tribos. Esse intercâmbio cultural promove grandes aglomerações com contato inter-humano e conseqüente transmissão não só do $S$. scabiei mas também de outros agentes parasitários. Sete aldeias da etnia Terena estão localizadas no município de Miranda, e segundo informações do Cacique da aldeia Moreira, as visitas intertribais são freqüentes, seja por motivos de festas, visitas familiares e até mesmo por interesses políticos. Os fatores citados aproximam esses povos, favorecendo a dispersão do agente da escabiose.

Nossos resultados são inferiores aos percentuais encontrados por outros autores, porém essa equivalência poderá aumentar ao ser dada continuidade ao projeto para examinar índios da etnia Terena de outras aldeias, cujo padrão de vida é muito inferior ao dos índios da aldeia Moreira. 
Os indivíduos parasitados foram orientados e medicados com Benzoato de Benzila, medicamento produzido e gentilmente fornecido pelo Dr Aluízio Antonio de Santa Helena, Diretor da Farmácia Universitária da Universidade Iguaçu.

\section{Citações e Formatação das Referências}

De acordo com Fulano (2003), citar corretamente a literatura é muito importante. Reparem que a citação de autores ao longo do texto é feita em letras minúsculas, enquanto que a citação de autores entre parênteses, ao final do parágrafo, deve ser feita em letra maiúscula, conforme indicado no próximo parágrafo.

$\mathrm{Na}$ verdade, citar trechos de trabalhos de outros autores, sem referenciar adequadamente, pode ser enquadrado como plágio (BELTRANO, 2002).

Para as referências, deve-se utilizar texto com fonte Times New Roman, tamanho 10, espaçamento simples, exatamente conforme aparece nas referências aleatórias incluídas a seguir. As referências devem aparecer em ordem alfabética e não devem ser numeradas. Contudo, o uso de marcadores é aconselhável. Todas as referências citadas no texto, e apenas estas, devem ser incluídas ao final, na seção Referências.

\section{Referências}

- ALVAREZ, R. R., CAMPBELL, I. \& FRIEDMAN, H. Dermatoses entre os Xavantes da área indígena Pimenta Barbosa, Mato Grosso, Brasil, Cadernos de Saúde Pública, n.7 v.4: 581-584, 1991.

- BAtistA, R. S.;GOMES, A. P.; IGREJA, R. P. \& HUGGinS, D. W. Medicina Tropical. Ed. Cultura Médica, Rio de Janeiro, p. 820-821, 2001.

- LOFREDO, S. M.; OLIVEIRA, C. B.; RODRIGUES. D; PEREIRA, I. M. T. \& MAEDA, S. M. Investigação e controle de epidemia de escabiose: uma experiência educativa em aldeia indígena. Rev. Sociedade e Saúde, n.1 v.10, 2001.

- MAnDell, G. L.; BennetT, J. E. \& DOLIN, R. Principles and Practice of Infectious Diseases. 5 ed., Ed. Churchill Livingstone, New York, p. 2974-2976, 2000.

- MENDES, J. P. V. Educação, saúde e liberdade: tríade para o desenvolvimento. Rev. Bras. Saúde, n.1 v.1: 4-12, 1990. 
- NEVES, D. P.; MELO, A. L., GENARO, O. \& LINARDI, P. M. Parasitoigia Humana, 9 ed,, Ed. Atheneu, Rio de Janeiro, p. 467-471, 1998.

- OBANJO, O. O. An outbreak of scabies in a teaching hospital. Infect. Control. Hosp. Epidemiol., n.22: 13-18, 2001.

- ORKIN, M. \& MAINBACH, H. I. Cutaneus infections and insect bites. Marcel Dekker Inc., New York, p. 139, 1985.

- ORKIN, M. Scabies in AIDS. Rev. Dermatol.,n.12 v.9, 1993.

- REY. L. Parasitologia, 2 ed., Ed. Guanabara Koogan, Rio de Janeiro, p. 658-659, 1991.

- SILVA, D.; REBELLO, P. B.; MORAES, F. \& BRITO, A. Escabiose: relato de uma epidemia. An. Bras. Dermatol, n.60 v.3: 135-136, 1985.

- VERONESI, R. \& FOCACC1A, R. Tratado de Infectologia, 2 ed. Ed. Atheneu, Rio de Janeiro, p. 1496-1497, 2002

\section{Informações bibliográficas:}

Conforme a NBR 6023:2002 da Associação Brasileira de Normas Técnicas (ABNT), este texto científico publicado em periódico eletrônico deve ser citado da seguinte forma: NORBERG, A. N.; PILE, E. A. M.; QUEIROZ, M. M. C.; SANTA HELENA, A. A.; NORBERG, P. R. B. M.; SANCHES, F. G.; TORRES, A. C.. Incidência de Escabiose entre Índios da Etnia Terena. Cadernos UniFOA, Volta Redonda, ano 1, n. 2, nov. 2006. Disponível em: <http://www.unifoa.edu.br/pesquisa/caderno/edicao/02/78.pdf> 